\title{
Light stimuli and circadian clock affect neural development in Drosophila melanogaster
}

Eleni Dapergola ${ }^{1,3}$, Pamela Menegazzi ${ }^{2}$, Thomas Raabe ${ }^{1 *}$, Anna Hovhanyan ${ }^{1 *}$

1 Institute of Medical Radiation and Cell Research, Biozentrum, University of Würzburg, 97074 Würzburg, Germany.

2 Neurobiology and Genetics, Theodor Boveri Institute, Biozentrum, University of Würzburg, 97074 Würzburg, Germany.

3 Current address: Molecular Biosciences, Institute for Biophysical Chemistry, Goethe University Frankfurt, 60323 Frankfurt am Main, Germany

* correspondence: anna.hovhanyan@uni-wuerzburg.de, thomas.raabe@uni-wuerzburg.de 


\begin{abstract}
Endogenous clocks enable organisms to adapt their physiology and behavior to daily variation in environmental conditions. Metabolic processes in cyanobacteria to humans are effected by the circadian clock, and its dysregulation causes metabolic disorders. In mouse and Drosophila were shown that the circadian clock directs translation of factors involved in ribosome biogenesis and synchronizes protein synthesis. However, the role of clocks in Drosophila neurogenesis and the potential impact of clock impairment on neural circuit formation and function is less understood. Here we demonstrate that light stimuli or circadian clock causes a defect in neural stem cell growth and proliferation accompanied by reduced nucleolar size. Further, we define that light and clock independently affect the InR/TOR growth regulatory pathway due to the effect on regulators of protein biosynthesis. Altogether, these data suggest that alterations in growth regulatory pathways induced by light and clock are associated with impaired neural development.
\end{abstract}




\section{Introduction}

Endogenous circadian clocks are highly conserved and enable organisms to adjust their physiology and behaviour to the day/night cycle. All circadian clocks 1) synchronize to the environment through input pathways, 2 ) rely on central molecular oscillators, which generate the rhythm and thereby keep circadian time, and 3) transmit time information to modulate the organism behaviour and physiology through output pathways. Processes modulated by the circadian clock include feeding behaviour, locomotor activity, body temperature, hormone level, and metabolic activity (Allada \& Chung 2010, Dubowy \& Sehgal 2017, Green et al. 2008).

TheA hierarchical network of clocks located in different tissues controls all these rhythmic processes. The master clock is located in the central nervous system (CNS) and synchronizes organ and tissue clocks (Glossop \& Hardin 2002, Green et al. 2008). The mammalian master clock is in the suprachiasmatic nuclei of the hypothalamus and consists of $\approx 15000$ clock neurons (Liu et al. 2007), whereas in Drosophila the master clock consists of a group of 150 clock neurons located in the lateral and dorsal brain (Hermann-Luibl \& Helfrich-Förster 2015). The molecular clock machinery is conserved across different species and consists of transcriptional-translational feedback loops (TTFL) to maintain the rhythmic cycling of gene expression (Patke et al. 2020). Briefly, circadian activators trigger transcription of repressor genes which, upon translation, feedback to suppress their own transcription. In Drosophila, these circadian activators are Clock (CLK) and Cycle (CYC), which form a heterodimeric protein complex to trigger the transcription of the circadian repressors, period (per) and timeless (tim), as well as many other target genes (Dubowy \& Sehgal 2017). PER and TIM accumulate in the cytoplasm (Allada \& Chung 2010, Dubowy \& Sehgal 2017). A complex interplay of light-dependent degradation, initiated by the blue light photoreceptor CRYPTOCHROME (CRY) (Collins et al. 2006, Emery et al. 1998, Emery et al. 2000), and multiple phosphorylation events regulate the accumulation of PER/TIM heterodimers and their timely translocation into the nucleus to inhibit the transcriptional activity of CLK/CYC (Hardin \& Panda 2013). Most core clock components are transcriptional regulators modulating the expression of many clock controlled genes in a tissue specific manner (Abruzzi et al. 2011, Rey. et al. 2011, Storch et al. 2002, McCarthy et al. 2007).

The clock in the CNS regulates different biological rhythms of fly, e.g. locomotor activity, sleep, eclosion, whereas circadian control of metabolism mostly depends on peripheral oscillators (Allada \& Chung 2010, Green et al. 2008). One of the major peripheral clock in mammals is placed in the liver, which regulates among others metabolism by combining environmental and central clock impulses (Lamia et al. 2008). However, limited food conditions might set the peripheral clock without any involvement of the master clock, indicating that limited nutrition is an external cue to entrain the peripheral oscillators (Damiola et al. 2000, Hara et al. 2001). In Drosophila, the fat body takes over the liver function where the clock regulates feeding behaviour and nutrient storage (Xu et al. 2008). In response to nutritional cue, the larval fat body generates mitogen that resumes the cell growth and cell-cycle re-entry in CNS (Britton \& Edgar 1998). Thus, regulation of metabolism guaranteeing supply of dietary nutrition plays a key role in the development of the CNS (Sousa-Nunes et al. 2011).

During development, the Drosophila CNS is generated from neuroblasts (NB) (Homem \& Knoblich 2012, Hakes \& Brand 2019), the progenitor cells of the nervous system. Two waves of neurogenesis, embryonic and larval, ensure CNS development and both correlate with changes in NB size. During the embryonic phase NBs go through a limited number of 
divisions, diminishing in size with each division until they become quiescent. The second wave of neurogenesis, during larval and pupal stages, starts with the exit of NBs from quiescence in a nutrition-dependent manner (Britton \& Edgar 1998, Chell \& Brand 2010). In contrast to the embryonic NBs, the larval NBs maintain their original size by regrowing after each division. This continues until the end of neurogenesis, where again NBs decrease in size and exit from the cell cycle.

The Drosophila central brain has three different types of NBs, which differ by their division modes: Type 0, Type I and Type II. Typically, NBs, like all other stem cells, divide asymmetrically to self-renew and to generate a daughter cell. Daughter cells generated by Type 0 NBs directly differentiate into neurons (Hakes \& Brand 2019, Ramon-Cañellas et al. 2018). Contrarily, the division of Type I NBs give rise to ganglion mother cells (GMCs), which divide once more to generate two neurons. Within approximately 100 Type I NBs the four mushroom body (MB) NBs are exceptional, because they proliferate throughout development without a quiescence phase to give rise to the MBs, important structures for the learning and memory processes (Ito \& Hotta 1992, Heisenberg 2003, Lin et al. 2013). Type II NBs deposit 12 neurons by each division through intermediate neural progenitors (INPs), which are generated after each division of Type II NBs (Bello et al. 2008, Boone \& Doe 2008, Wang et al. 2014, Bowman et al. 2008).

NBs exit quiescence and reactivate proliferation depending on the nutritional state of the organism. The major growth regulator pathway is governed by the insulin receptor (InsR)/ target of rapamycin (TOR) signaling. The pathway is triggered by insulin-like peptide (ILPs) generated in insulin-producing glial cells (IPCs), which receive nutritional signals from the fat body (FB) (Sousa-Nunes et al. 2011, Chell \& Brand 2010, Géminard et al. 2009). The TOR pathway might be activated independently from InR pathway, via direct cellular nutrient sensing (González \& Hall 2011). The interplay between InsR and TOR pathways regulates cell growth through a variety of effector proteins at the levels of gene expression, ribosome biogenesis, and protein synthesis (Hietakanges \& Cohen 2009, Russel et al. 2011).

Approximately $10 \%$ of all genes are regulated in a circadian manner (Bass \& Takahashi 2010, Doherty and Kay 2010, Wijnen et al. 2006, Ueda et al. 2002, Hughes et al. 2012). Therefore, dysregulation of the circadian system contributes to the pathophysiology of many diseases; most prominent of those are psychiatric disorders and metabolic diseases (Bellet \& Sassone-Corsi 2010, Zordan \& Sandrelli 2015). Despite the well-established link between the circadian system and physiological processes, the influence of the circadian clock on neuronal development and therefore its potential impact on neural circuit formation is poorly understood. Since the circadian system and cellular signalling pathways are highly conserved from invertebrate to mammals, Drosophila is a powerful model for discovering and understanding how developmental processes might be modulated by circadian rhythm. To reveal this link, we compared the neural development of wild-type and clock mutant flies exposed to different light regimes. First, we showed that disturbed circadian clock, as well as different light conditions, affect the NB growth and proliferation. Second, we found that these flies also showed a significant reduction of nucleolus size in the NBs, indicating that rRNA production and further processing might be disturbed, potentially leading to cell proliferation defects. Finally, based on our findings we analysed the effect of light and circadian clock on the InR/TOR growth regulatory pathway and found that both light and clock impair this pathway. Specifically gene expression and activity of Akt, as a regulator of TOR via the InR pathway, and S6K (RPS6-p70-protein kinase) as a downstream target of TOR and major regulator of nutrient metabolism and cell growth, are disturbed when the light regime is changed or clock function is abrogated. 


\section{Results}

\section{Circadian clock and light independently control cell growth in the larval brain}

At all developmental stages animals sense and respond to changes in both external and internal conditions, and the combination of this information regulates behaviour and metabolism to benefit from available resources and to maintain cellular homeostasis. Metabolism is important for the proper growth and development of an organism (Koyama et al 2020) and many aspects of metabolism and cellular physiology are controlled by endogenous circadian rhythms (Green et al. 2008, Bellet \& Sassone-Corsi 2010, Shi \& Zheng 2013). CNS development of Drosophila is a prominent example to investigate the mechanism, how an organism copes with changes in environmental conditions, e.g. under nutrient deprivation (Lanet \& Maurange 2014). Therefore, we investigated whether disruption of the circadian clock influences the growth of neuroblasts during development. Moreover, we asked whether light, independently from the clock, also affects cell growth. To test the clock effect on cell growth, we measured NBs size in $3^{\text {rd }}$ instar larval brains of wild type and per ${ }^{01}$ mutants (which lack a functional clock) grown under light-dark (LD) condition. NBs were marked with specific markers (aPKC and Miranda). A similar experiment was done with wild type flies kept in LD, constant darkness (DD, where the molecular clock still maintains a rhythm of approximately 24 hours without being reset by light stimuli) and constant light (LL, where the circadian clock is not functional anymore due to the constant activation of the photopigment CRY). In addition, to control the effects of the light-dark cycles - not directly linked to the resetting of the molecular oscillator by CRY - we included cry ${ }^{01}$ mutants in our experiments. We found significantly smaller NBs in larvae lacking a functional clock, namely per ${ }^{01}$ mutants and wild type kept in LL, as well as in larvae with a functional oscillator unable to directly reset by light transitions, i.e. cry ${ }^{01}$ mutants and wild type flies raised in DD (Figure1B-C). As the strongest effects were observed in per ${ }^{01}$ mutants and wild type grown under DD condition, all further experiments were performed using these two groups.

In order to distinguish whether the observed growth defect exists from the beginning of the second wave of neurogenesis or it is a later effect, we conducted a staging experiment by measuring the size of NBs during larval development at 22 ( $1^{\text {st }}$ instar), 36 ( $2^{\mathrm{d}}$ instar) and 96 ( $3^{\text {rd }}$ instar) hour after larval hatching $(A L H)$. To analye the late $1^{\text {st }}$ instar larval NBs were chosen, since NB resume reactivation in a couple of hours after hatching and sequentially continue it till the end of $1^{\text {st }}$ instar larval stage. A significant cell growth defect was observed from the late $1^{\text {st }}$ instar larval stage (Figure 1D) much more pronounced at later stages.

Thus, our findings indicate that not only the endogenous clock but also light as an environmental factor are needed to control the proper NB growth in the larval brain.

\section{Circadian clock and light are required for cell proliferation}

The balance between cell growth and proliferation is important to maintain the proper generation, as well as repair of tissues (Maurange et al. 2008). Since we found evidence that the endogenous clock and light have an impact on growth of NBs, we assumed that the proliferation might be affected by the clock and light regime. Therefore, we determined the number of progeny cells for two different subtypes of NBs: mushroom body (MB) and Type II NBs. Since the number of these NBs are only four and eight in each hemisphere, respectively, it is possible to follow the generation of progenies using specific markers. MB and Type II NBs have different modes of division. MB NBs are dividing asymmetrically to 
give rise to a self-renewing NB and a GMC, which divides one more time to generate two neurons (Figure 2A). Type II NBs divide asymmetrically to generate a self-renewing NB and a transient amplifying cell called immature intermediate neural progenitor (iINP), which by transcriptional changes becomes a mature INP (mINP). Each mINP divides asymmetrically three to five times to form another mINP and a GMC giving rise to two neurons (Figure 2B). To identify MB NBs and their progenies, in addition to Miranda (Mir) as general NB marker, anti-Tailless (TII) and anti-Dachshund (Dac) were used to specifically label MB lineages (Kraft et al. 2016, Kurusu et al. 2009, Kurusu et al. 2000). TIl is specific for GMCs originating from MB NBs and Dac is a marker for derived neurons (Kenyon cells) surrounding MB NBs. To distinguish Type II NBs, UAS::mCD8-GFP was expressed under the control of wor-Gal4, ase-Gal80 (Neumüller et al. 2011). Additionally, anti-Deadpan (Dpn) and anti-Asense (Ase) antibodies were used to differentiate between progenies of Type II NBs, as Dpn is expressed only in mINPs and Type II NBs, whereas Ase labels iINPs, GMCs and is also co-expressed in mINPs (Bowman et al. 2008, Walsh \& Doe 2017). To ensure whether the growth defect is restricted to a certain type of NBs or it is a general effect, we also measured NB size. For Immunohistochemical assay $3^{\text {rd }}$ instar larval brains were used. Cell size analysis revealed that both types of NBs are significantly reduced in size when compared to wild type NBs (Figure 2C and $\mathrm{E}$ ). This indicates that light input and a functional clock are required for all NBs to maintain proper cell size. For an analysis of the proliferation capacity of MB or Type II NBs, we counted $\mathrm{TII}^{+}$GMCs and Dpn+ INPs generated from single NBs, respectively. As it is shown in Figure 2D and $F$, in both cases there is a pronounced reduction in the number of progenies. These results demonstrate that the circadian clock and light are required for control of the proliferation of central brain NBs.

\section{Effect of endogenous clock and light on nucleolar size and transcriptional activity}

A mechanism, that potentially is responsible for reduced size and consequently proliferation defects involves the disturbance of cell asymmetry and spindle misorientation. Mainly cellintrinsic processes control NB division. An apical-basal polarity axis is established by the apical enrichment of the Par protein complex components Bazooka, Par6, and aPKC mediating also proper spindle orientation along apico-basal axis. In addition, the Par complex controls basal enrichment of cell fate determinants (the Miranda (Mir)-Brain tumor (Brat)-Prospero (Pros) and Numb-Partner of Numb (Pon) complexes) specifying GMC fate. Upon asymmetric division, apical Par-complex proteins are inherited by the self-renewed NBs whereas basally localied factors are inherited exclusively by the GMC (Homem \& Knoblich 2012, Hakes \& Brand 2019, Chia et al. 2008). Staining for aPKC and Mir to identify apical and basal cortex (together with phospho-histone $\mathrm{H} 3(\mathrm{pH} 3)$ as a mitotic marker) revealed that central elements of asymmetric cell division (cell polarity and spindle orientation) are not affected (Figure 3A) for each tested genotype and light regime. Hence, impaired cell growth and proliferation is not due to disturbance cell polarity.

Another possible explanation for the compromised proliferation observed in MB and Type II NBs (Figure 2D \& F) could be the NBs inability to produce enough proteins to fulfill the requirements of the cell to gain appropriate mass and size before division. The efficiency of protein biosynthesis depends on proper nucleolar function as a site for rRNA transcription/proccesing and assembly of ribosomes. Thus, the nucleolus is a critical player to maintain cell homeostasis and directly affects cell growth and proliferation. Nucleolar size positively correlates with the amount of rRNA biosynthesis (Stepinski 2018). Specifically, it is directly related to RNA polymerase I transcriptional activity and nucleolar size is the 
largest at the end of G2 phase, before cell division take place (Maszewski \& Kwiatkowska 1984, Hernandez-Verdun 2011). To verify, whether light or disturbed circadian clock influence RNA synthesis, we compared the size of NBs nucleoli in per ${ }^{01}$ mutant and wild type grown under DD and LD conditions. NBs were marked using aPKC (green) and Mir (red), Lamin (blue) to outline the nuclear membrane and Nop5 (green) was used as a nucleolar marker.

To find out whether light or clock affects nucleolar size we analyze interphase cells because of the presence of the nucleolar membrane. Nucleolar size of NBs in per01 mutant and wildtype larvae grown under DD conditions were significantly smaller compared to wild type (Figure $3 C$ ). Moreover, classification of nucleolar size, as large $\left(\geq 9 \mu \mathrm{m}^{2}\right)$, intermediate $(\geq 6$ $\left.\mu \mathrm{m}^{2}\right)$ and small $\left(<6 \mu \mathrm{m}^{2}\right)$, revealed the strongest effect in wild-type larvae grown under DD conditions, where $72 \%$ of the nucleoli were small and only $27 \%$ of them at intermediate size. In per ${ }^{01}$ mutants, the nucleolar size was equally (46\%) distributed between intermediate and small sizes, whereas the nucleolar size of wild type in LD conditions were mostly distributed between large (42\%) and intermediate (48\%) sizes, with only $10 \%$ nucleoli being small (Figure 3D).

Taken together, these results provide evidence that the capability of NBs of per01 mutants and wild-type animals grown under DD to synthesize proteins might be impaired, which finally could lead to the observed cell growth defects.

\section{Expression and activation of InR and Tor signalling are controlled by the light regime and the circadian clock}

Reactivation of NBs after dormant state and their regrowth after each division to sustain proper CNS development requires InR/TOR signalling pathway (Sousa-Nunes et al. 2011, Chell \& Brand 2010). Impaired function of InR/TOR pathway results in reduced cell size and proliferation as it is required for regulation of dS6K activity, a downstream target of TOR growth pathway, and one of the major regulators of nutrient metabolism and cell growth due to its role in ribosome biogenesis and protein translation (Zhang et al. 2000, Raught et al 2004, Shahbazian et al 2006). Our findings concerning NB and nucleolar size reduction and the role of nucleolus in the maintenance of cell homeostasis lead to the assumption that light might have a regulatory effect on InR/TOR growth pathways. Therefore, we tested the impact of the light on transcriptional and post-transcriptional regulation of dAkt, which is an important signalling molecule in InR pathway (Potter et al. 2002, Ruggero \& Sonenberg 2005, Nave et al. 1999). Next, we tested dS6k, a critical effector of TOR growth pathway, which is important for a high level of protein synthesis due to its phosphorylation. First, we checked whether the transcription of $d A k t$ and $d S 6 k$ is disturbed under DD condition. Quantitative reverse transcription (RT)-PCR analyses showed that $d A k t$ and $d S 6 k$ mRNA transcriptional levels are reduced at most time points during subjective day and night. However, there are no significant differences between flies grown under LD and DD conditions (Figure 4A and C).

In the further test, we did not observe any differences in dAkt protein total expression level during a period of 24 hours between two experimental groups (Figure 4B, Figure 4-figure supplementary 1). Interestingly, although there was no change at transcriptional and total protein expression levels, significant differences were evident in phosphorylation of dAkt and dS6k at most of the time points under DD conditions. Both kinases showed a significant reduction of the total phosphorylation level (Figure $4 B$ and $D$ ) resulting in their reduced activity. 
We checked also the regulatory effect of the circadian clock on gene and protein expression levels of dAkt and dS6k. Similarly, to the DD condition we did not observe differences in dAkt protein total expression level between wild type and per ${ }^{01}$ (Figure 5B, Figure 5-figure supplementary 1). However, in contrast to the light effect, the RT-qPCR analysis confirmed that the disruption of the circadian clock results in reduced expression of $d A k t$ and $d S 6 k$ mRNAs (Figure 5A and C). In addition, the activity of dAkt and dS6k was severely affected in the circadian clock mutant flies compared to DD condition, exhibiting a robust decrease of the phosphorylation level of both kinases in per01 mutants (Figure 5B and D).

These results indicate that the activation of two important components of InR/TOR growth pathways is under influence of light and the circadian clock. The impairment of the function of growth pathways via reduction of phosphorylation of dAkt and dS6K might lead to cell growth and proliferation suppression. 


\section{Discussion}

Regulation of neuroblast growth and proliferation by light and the circadian clock

Metabolic homeostasis relies on accurate circadian timing (Green et al 2008, Eckel-Mahan \& Sassone-Coesi 2013). The circadian clock is conserved across different species and maintains the rhythmic cycling of gene expression (Patke et al 2020). Many aspects of metabolism and cellular physiology are controlled by endogenous circadian rhythms. In mammals, there is evidence that a disrupted circadian clock causes severe disturbances in rhythmic gene expression (Bellet \& Sassone-Corsi, 2010), many of them being involved in metabolism (Panda et al, 2002). Furthermore, environmental factors such as light, temperature or nutrition can externally modulate these autonomous rhythms and synchronize the endogenous clock with the environment. Animals with disrupted circadian system, caused by the exposure to shifted light/dark cycles, show various pathological symptoms including metabolic deficits (Mota et al. 2017, Maury 2019, Barclay et al. 2012, Marcheva et al. 2010) and cognitive difficulties (Gerstner et al. 2008).

Cell proliferation and growth are tightly coordinated to ensure proper animal development. In Drosophila, the two waves of neurogenesis (embryonic and postembryonic) are separated by a quiescence state. After exiting from quiescence, NBs first enlarge before they start to proliferate (Truman \& Bate 1988, Colombani et al. 2003, Chell \& Brand 2010). Re-entry to the cell cycle fails when NBs are unable to enlarge due to the lack of nutrition (Britton and Edgar 1998). Nutrient dependent reactivation of NBs is a good model to show how stem cells get adapted to environmental changes. In this study we show that NB growth and proliferation require both clock function and light information. In particular, we demonstrate that different types of CB NBs fail to reach proper size in larvae raised without light (DD) or lack a functional clock (per ${ }^{01}$ ) (Figure $1 \mathrm{~B}$, Figure $2 \mathrm{~A}$ and $\mathrm{B}$ ) and this phenotype is observed from the beginning of the second wave of neurogenesis (Figure 1D). The major part of adult central nervous system is generated during second wave of neurogenesis. To maintain continuous proliferation and to ensure generation of adult nervous system, postembryonic NBs must grow and regain their size between rounds of divisions (Ito \& Hotta 1992, Maurange et al. 2008, Siegrist et al. 2010). Next, we assessed the requirement of light and the circadian clock in the proper proliferation of cells. We observed significant reduction of number of progenies for flies under DD condition and with disrupted clock (Figure 2D and F). Since the process of asymmetric cell division itself was not affected (Figure 3A), decreased NB size could provide an explanation for impaired NB proliferation. Recent findings suggest that NB reactivation requires nutritional input sensed by the fat body, which in turn activates NB ensheating glial cells by fat body derived signal (FDS) to produce Insulin-like peptides (ILP). Reactivation of NBs requires ILP signals and amino acid uptake, which stimulate the InR/TOR signaling pathways to trigger first growth of the neuroblast before they resume proliferation (Sousa-Nunes et al. 2011, Chell \& Brand 2010). On the other hand, glial cells also express Activin-like peptides (ALPs) which have a mitogenic effect on NBs and are important for stimulating NB division (Zhu et al. 2008). In this regard, it will be of interest to find out whether glial expression of ILPs and ALPs are affected under DD condition and in clock mutants. 
bioRxiv preprint doi: https://doi org/10.1101/2020.08.07.241208; this version posted August 7, 2020. The copyright holder for this preprint (which was not certified by peer review) is the author/funder, who has granted bioRxiv a license to display the preprint in perpetuity. It is made available under aCC-BY-NC-ND 4.0 International license.

\section{Coordination of cellular growth regulatory pathways by light and the circadian clock}

Prior to proliferation, cells must gain appropriate mass and size which is directly linked to a high demand for proteins. Major steps for protein biosynthesis are the following: RNA synthesis via rDNA transcription, ribosome biogenesis, translation and post-translational modification. In consideration of the high metabolic cost of RNA synthesis and ribosome biogenesis, protein biosynthesis represents one of the main metabolic activities in growing and dividing cells. In mammals, the circadian clock coordinates ribosome biogenesis on transcriptional and translational levels (Jouffe et al. 2013). In particular, authors have shown that circadian clock coordinates mRNA translation via control of the expression and activation of translation initiation factors. The signalling pathways regulating these processes are rhythmically activated in a clock-dependent manner. Interestingly, translated mRNAs are mostly involved in ribosome biogenesis (Jouffe et al. 2013). The nucleolus is the site where RNA synthesis and ribosome biogenesis takes place, thus the size of the nucleolus correlates with cell growth ability. Our observations that flies under DD condition and flies with depleted clock function have drastically reduced nucleoli (Figure $3 C \& D$ ) indicated that the observed growth and proliferation defect could be due to the failure of protein biosynthesis.

The major growth regulatory pathway, i.e. InR/TOR, is highly conserved between different organisms (Hietekangas \& Cohen 2009). Most of the genes regulated by TOR signaling pathway are involved in rDNA transcription, ribosome biogenesis and translation initiation (Guertin et al. 2006, Grewal et al. 2007). Furthermore, Drosophila larvae deficient for dTOR show a reduced nucleolar size and developmental arrest (Zhang et al. 2000). The observed cell size phenotype raised the question, how the light and circadian clock might regulate cell growth and proliferation? Do they have a role in cell growth regulated by the InR/TOR pathways?

The TOR activation, as the major effector of InR pathway to regulate protein biosynthesis, requires the Akt-phosphorylation event (Gao \& Pan 2001, Potter et al. 2002, Inoki et al. 2002). Independent from InR, the TOR pathway also gets activated trough nutritional or amino acid sensing mechanisms (Shim et al. 2013, Colombani et al. 2003, Kim et al. 2008). In both cases, the growth regulation is triggered by phosphorylation of TOR downstream effector proteins. In this report, our focus was on Akt as a major regulator of TOR pathway via InR signaling and one of its major downstream effector protein ribosomal protein kinase p70 (dS6K). dS6K phosphorylates and activates several substrates essential for mRNA translation initiation and translation efficiency (Holz et al. 2005, Dorrelo et al. 2006, Ma et al. 2008). Additionally, activated dS6k plays a role in small ribosome biogenesis via phosphorylation of ribosomal protein S6 (Hietekangas \& Cohen 2009, Saxton \& Sabatini 2017).

The findings presented here provide correlation that light and the circadian clock control cell growth and proliferation through regulation of InR/TOR pathways. The expression of $d A k t$ and $d S 6 k$ was not rhythmic and their level did not differ significantly between wildtype grown under LD and DD within a 24 hours period (Figure 4A and C). However, the activity of dAkt and dS6K was significantly reduced in flies kept under constant darkness at several time points, during a period of 24 hours (Figure 4B and D). We also found, that disrupted clock in larvae has a stronger effect not only on the activity of dAkt and dS6K (Figure 5B and D) but also on their gene expression level (Figure 5A and C). These observations indicate that suppressed NB growth and proliferation might be a result of disturbed TOR activation by Akt, followed by inhibition of translation initiation or small ribosome subunit biogenesis by S6K.

The survival rate and fitness of an organism are regulated by the ability to adapt to environmental changes by adjusting developmental growth, metabolism and behavior. Dependent on different environmental conditions (temperature, light, nutrient availability), 
animals develop at different rates to adults with different sizes that suit prevailing environmental conditions (Nijhout 2003, Colombani et al. 2003, Shiengelton et al. 2009, Li \& Gong 2015). Nutrition dependent hormonal signaling pathways and the endocrine system regulate these processes (Hietakangas \& Cohen 2009, Tennessen \& Thummel 2011, Boulan et al. 2015). Several experiments in mice models provide evidence for the requirement of circadian rhythms in metabolic homeostasis and energy metabolism (Marcheva et al. 2010, Paschos 2015, Rudic et al. 2004, Yang et al. 2009). Furthermore, the circadian clock regulates rhythmic ribosome biogenesis, on the transcriptional and translational level, through coordination of rhythmic activation of InR/TOR pathways (Jouffe et al. 2013). Our current findings constitute important communication that the major growth regulatory pathways are orchestrated by clock independent and the clock dependent regulation to coordinate proper organism development. 


\section{Material and methods}

\section{Fly Stocks and Genetics}

Flies were maintained at $25^{\circ} \mathrm{C}$ on standard cornmeal food in a $12 \mathrm{~h}$ light-dark (LD) cycle. Canton Special (CS) was the control and genetic background for clock mutant flies: per01 (Konopka and Benzer, 1971), also was used in light entrainment experiments. CS was used also for light entrainment experiments. To mark Type II NBs, the wor-Gal4, ase-Gal80 driver line was used (Neumueller et al. 2011) to express UAS::mCD8-GFP. For RNA isolation or protein extraction, after laying eggs, vials were entrained in a $12 \mathrm{~h}$ LD cycle or shifted into constant darkness until the $3^{\text {rd }}$ instar larvae stage. Relative to Zeitgeber time 0 (ZTO) as the time of lights-on during the LD cycle and circadian time 0 (CTO) as the time corresponding to subjective lights-on during free running in DD, larvae were collected in a ZTO-ZT4-ZT8ZT12-ZT16-ZT20-CT0-CT4-CT8-CT12-CT16-CT20 schedule and dissected. Isolated larval brains were collected either in Trizol (for RNA extraction) or in Laemmli buffer (for protein extraction).

\section{Larval staging}

Immediately after hatching, larvae were collected from apple juice plates at 30 minutes intervals and transferred to standard fly food plates with yeast. per ${ }^{01}$ mutants, wild-type larvae under LD and DD light regime were kept at $25^{\circ} \mathrm{C}$ until they reached the desired age. Before preparation, larval stages were determined by means of spiracle morphology. 36 hours old larvae were L2, 48 hours and older larvae were L3.

\section{Immunohistochemistry (IHC)}

For immunostainings, larval brains were dissected in PBS (10 mM Na2HPO4,2 mM $\mathrm{KH}_{2} \mathrm{PO}$, $\left.2.7 \mathrm{mM} \mathrm{KCl}, 137 \mathrm{mM} \mathrm{NaCl}\right)$ and fixed on ice for $25 \mathrm{~min}$ in PLP solution (2\% paraformaldehyde, $10 \mathrm{mM} \mathrm{NalO} 4,75 \mathrm{mM}$ lysine, $30 \mathrm{mM}$ sodium phosphate buffer, pH 6.8). All washings were done in PBT (PBS plus $0.3 \%$ Triton X-100). After blocking in PBT containing $3 \%$ normal goat serum for $2 \mathrm{~h}$, brains were incubated overnight with combinations of the following primary antibodies: rabbit anti-protein kinase $\mathrm{C}$ (anti-PKC) clone C20 (1:1000; Santa Cruz Biotechnology), rabbit anti-phospho-histone H3 (1:2500; Millipore Upstate), rat anti-Miranda (1:300; Abcam, clone CD\#5-7E9BG5AF4), mouse antiMiranda (1:20; F. Matsuzaki, Kobe, Japan), rabbit anti-Nop5 (1:600; G. Vorbrüggen, Göttingen, Germany), chicken anti-GFP (1:1000; Abcam), rabbit anti-Asense (1:400; J.DiazBenjumea, Madrid, Spain), guinea pig anti-Deadpan (1:1000; J. Knoblich, Vienna, Austria), AlexaFluor546-Phalloidin (1:100; Molecular Probes), mouse anti-Dachshund (1:10; clone mAbdac2-3, Developmental Studies Hybridoma Bank, lowa City, IA, United States), rabbit anti-Tailless (1:600; J. Reinitz, Chicago, Illinois, United States), guinea pig anti-lamin DmO (1:300; G. Krohne, Wuerzburg, Germany). Secondary antibodies were conjugated with Alexa Fluor 488 (Molecular Probes), Cy3, Cy5, or DyLyte488 (Dianova). After extensive washing in PBT, brains were embedded in Vectashield. Confocal images were collected with a Leica SPE microscope. Image processing was done with ImageJ $1.46 \mathrm{r}$ software $(\mathrm{NIH}$, Bethesda, MD). 
Neuroblast and nucleolar areas were measured by the freehand selection tool of ImageJ $1.46 r$ software $(\mathrm{NIH}$, Bethesda, MA, USA). Neuroblasts were visualised by aPKC or Miranda, nucleoli by Nop5 antibodies.

\section{Neuroblast proliferation and IHC analysis}

Progenies of MB and Type II neuroblasts were marked with specific antibodies. Particularly, MB NBs daughter cells were marked with anti-TIl antibody, which specifically marks MB NB derived GMCs (Kurusu et al. 2009). Type II NBs and their lineages were marked with GFP by using UAS:: $m C D 8-G F P$ line under the control of the wor-Gal4, ase-Gal80 driver line (Neumueller et al. 2011). To specify between all types of the Type II NB lineages anti-Dpn and anti-Ase antibodies were used (Bowman et al. 2008, Walsh \& Doe 2017). MB NB derived GMCs and mINPs were counted with Amira ${ }^{\circledR}$ software using the Landmark selection.

\section{RNA isolation and RT-qPCR analysis}

Entrained larvae, as well as wild type and per ${ }^{01}$ mutant larvae were collected in PBS and placed on ice. Dissections of larvae were done within $30 \mathrm{~min}$ and brains were collected in Trizol. Total RNA was extracted from brains using TRIzol $^{\circledR}$ reagent according to the manufacturer's instruction $\left(\right.$ Ambion ${ }^{\circledR}$, Thermo Fisher Scientific, Waltham, MA, United States). First-strand cDNA was synthesized from $2 \mu \mathrm{g}$ of RNAusing High-Capacity cDNA Reverse Transcription Kits (Applied Biosystems, Thermo Fisher Scientific, Waltham, MA, United States). RT-qPCR was done using PowerUp ${ }^{\mathrm{TM}}$ SYBR ${ }^{\mathrm{TM}}$ Green Master Mix (Applied Biosystems, Thermo Fisher Scientific, Waltham, MA, United States) on a StepOnePlus ${ }^{\mathrm{TM}}$ (Applied Biosystems. Thermo Fisher Scientific, Waltham, MA, United States) real-time thermal cycler. Reaction mixtures contained $300 \mathrm{nM}$ of oligonucleotides (see Supplementary Table S1). RT-qPCR conditions were $2 \min 50^{\circ} \mathrm{C}$ and $2 \min 95^{\circ} \mathrm{C}$ holding steps, followed by 40 cycles of $15 \mathrm{~s} 95^{\circ} \mathrm{C}$ and $1 \mathrm{~min} 60^{\circ} \mathrm{C}$. Results were expressed as fold change in expression of the treated sample in relation to untreated samples and relative to the reference gene rp49. Mean \pm SEM was calculated at least from triplicate experiments from each of the three independent biological samples per genotype or different light regime.

The following primers were used to amplify the cDNA of target genes:

Akt (forward 5'-ACAGATCTAGTGTTGAAAAAAATATACCG-3' and reverse 5'ATGTCTCCTTGGTAGCTGAACTGCG-3'), $56 k$ (forward TTCTTAGAGGATACCACATGCTTC-3' and reverse 5'TGGTCAAAATTTCAGGTGCCATGTAC-3'), $\quad$ rp49 (forward 5'GCCCAAGATCGTGAAGAAGC-3' and reverse 5'-CGACGCACTCTGTTGTCG-3').

\section{Western Blot}

Lysates from wild-type or per ${ }^{01}$ larval brains were sonicated in 2x Laemmli, separated by SDS-PAGE and transferred to PVDF membranes. Blots were incubated overnight at $4{ }^{\circ} \mathrm{C}$ with the following antibodies: rabbit anti-phospho-Akt (Ser473) (1:1000; clone D9E, Cell Signaling), rabbit anti-Akt (1:1000, Cell Signaling, Denvers, MA, US), rabbit anti-phosphoDrosophila-p70 S6k (1:1000; Cell Signaling, Denvers, MA, US), mouse anti- $\alpha-T u b u l i n$ (1:5000, clone NDM1A, Merck, Darmstadt, DE). After incubation with HRP-coupled secondary antibodies, signal detection was done with the ECL Plus detection reagents (GE Healthcare Life Science, Buckinghamshire, UK) and a ChemoCam ECL Imager equipped 
with a 16 bit camera (Intas, Göttingen, DE). Exposure times were adjusted to allow for quantification of signal intensities within the dynamic range of the camera system.

\section{Data Analysis}

Cell and nucleolar size, as well as proliferation analysis, were analysed in the program Statistica $v$. 9. Distributions of variables did not deviate significantly from normality (Kolmogorov-Smirnov test; $P>0.2$ ). A one-way analysis of variance (ANOVA) was performed for statistical analysis. Axis lengths and areas were considered as dependent variables, and the strain (wild type versus mutant or LD light regime versus DD) was considered as an independent variable.

To calculate the significance between expression data differences, statistical analyses were performed using Mann-Whitney- $U$ - test (Origin Pro9.0.0 b45 software) to determine significant differences between genotypes. For multiple testing within one data set, the level of significance $p 0.05$ was adjusted with the Bonferroni correction factor. Graphs are presented as mean \pm the max and min size distribution or \pm SEM, asterisks depict the level of statistical significance ${ }^{* * *} p$ and ${ }^{* * *} p \leq 0.0001,{ }^{* *} p \leq 0.001$ and ${ }^{*} p \leq 0.01$. Graphs were generated in Prism6.

\section{Acknowledgments}

We would like to thank Dr. Vahan Serobyan for discussion and comments on the manuscript. We thank Kjara Sophia Pilch for assistance in RT-qPCR experiments.

This work was founded by the German Research Foundation (DFG, SFB 1047 "Insect Timing", Project A6 - T.R.) and the German Excellence Initiative to the Graduate School of Life Sciences, University of Würzburg (GSC106 - A.H.).

\section{Competing interests}

No competing interests declared 


\section{References}

1. Abruzzi, K. C., Rodriguez, J., Menet, J. S., Desrochers, J., Zadina, A., Luo, W., Tkachev, S., \& Rosbash, M. (2011). Drosophila CLOCK target gene characterization: implications for circadian tissue-specific gene expression. Genes \& development, 25(22), 2374-2386. https://doi.org/10.1101/gad.178079.111

2. Allada, R., \& Chung, B. Y. (2010). Circadian organization of behavior and physiology in Drosophila. Annual review of physiology, 72, 605-624. https://doi.org/10.1146/annurev-physiol-021909-135815

3. Barclay, J. L., Husse, J., Bode, B., Naujokat, N., Meyer-Kovac, J., Schmid, S. M., Lehnert, H., \& Oster, H. (2012). Circadian desynchrony promotes metabolic disruption in a mouse model of shiftwork. PloS one, 7(5), e37150. https://doi.org/10.1371/journal.pone.0037150

4. Bass, J., \& Takahashi, J. S. (2010). Circadian integration of metabolism and energetics. Science (New York, N.Y.), 330(6009), 1349-1354. https://doi.org/10.1126/science.1195027

5. Bellet, M. M., \& Sassone-Corsi, P. (2010). Mammalian circadian clock and metabolism - the epigenetic link. Journal of cell science, 123(Pt 22), 3837-3848. https://doi.org/10.1242/jcs.051649

6. Bello, B. C., Izergina, N., Caussinus, E., \& Reichert, H. (2008). Amplification of neural stem cell proliferation by intermediate progenitor cells in Drosophila brain development. Neural development, 3, 5. https://doi.org/10.1186/1749-8104-3-5

7. Boone, J. Q., \& Doe, C. Q. (2008). Identification of Drosophila type II neuroblast lineages containing transit amplifying ganglion mother cells. Developmental neurobiology, 68(9), 1185-1195. https://doi.org/10.1002/dneu.20648

8. Boulan, L., Milán, M., \& Léopold, P. (2015). The Systemic Control of Growth. Cold Spring Harbor perspectives in biology, 7(12), a019117. https://doi.org/10.1101/cshperspect.a019117

9. Bowman, S. K., Rolland, V., Betschinger, J., Kinsey, K. A., Emery, G., \& Knoblich, J. A. (2008). The tumor suppressors Brat and Numb regulate transit-amplifying neuroblast lineages in Drosophila. Developmental cell, 14(4), 535-546. https://doi.org/10.1016/j.devcel.2008.03.004

10.Britton, J. S., \& Edgar, B. A. (1998). Environmental control of the cell cycle in Drosophila: nutrition activates mitotic and endoreplicative cells by distinct mechanisms. Development (Cambridge, England), 125(11), 2149-2158.

11. Chell, J. M., \& Brand, A. H. (2010). Nutrition-responsive glia control exit of neural stem cells from quiescence. Cell, 143(7), 1161-1173. https://doi.org/10.1016/j.cell.2010.12.007 
12. Chia, W., Somers, W. G., \& Wang, H. (2008). Drosophila neuroblast asymmetric divisions: cell cycle regulators, asymmetric protein localization, and tumorigenesis. The Journal of cell biology, 180(2), 267-272. https://doi.org/10.1083/jcb.200708159

13. Collins, B., Mazzoni, E. O., Stanewsky, R., \& Blau, J. (2006). Drosophila CRYPTOCHROME is a circadian transcriptional repressor. Current biology : $C B$, 16(5), 441-449. https://doi.org/10.1016/j.cub.2006.01.034

14. Colombani, J., Raisin, S., Pantalacci, S., Radimerski, T., Montagne, J., \& Léopold, P. (2003). A nutrient sensor mechanism controls Drosophila growth. Cell, 114(6), 739749. https://doi.org/10.1016/s0092-8674(03)00713-x

15. Damiola, F., Le Minh, N., Preitner, N., Kornmann, B., Fleury-Olela, F., \& Schibler, U. (2000). Restricted feeding uncouples circadian oscillators in peripheral tissues from the central pacemaker in the suprachiasmatic nucleus. Genes \& development, 14(23), 2950-2961. https://doi.org/10.1101/gad.183500

16. Doherty, C. J., \& Kay, S. A. (2010). Circadian control of global gene expression patterns. Annual review of genetics, 44, 419-444. https://doi.org/10.1146/annurevgenet-102209-163432

17.Dorrello, N. V., Peschiaroli, A., Guardavaccaro, D., Colburn, N. H., Sherman, N. E., \& Pagano, M. (2006). S6K1- and betaTRCP-mediated degradation of PDCD4 promotes protein translation and cell growth. Science (New York, N.Y.), 314(5798), 467-471. https://doi.org/10.1126/science.1130276

18. Dubowy, C., \& Sehgal, A. (2017). Circadian Rhythms and Sleep in Drosophila melanogaster. Genetics, 205(4), https://doi.org/10.1534/genetics.115.185157

19. Eckel-Mahan, K., \& Sassone-Corsi, P. (2013). Metabolism and the circadian clock converge. Physiological reviews, 93(1), 107-135. https://doi.org/10.1152/physrev.00016.2012

20.Emery, P., So, W. V., Kaneko, M., Hall, J. C., \& Rosbash, M. (1998). CRY, a Drosophila clock and light-regulated cryptochrome, is a major contributor to circadian rhythm resetting and photosensitivity. Cell, 95(5), 669-679. https://doi.org/10.1016/s0092-8674(00)81637-2

21. Emery, P., Stanewsky, R., Helfrich-Förster, C., Emery-Le, M., Hall, J. C., \& Rosbash, M. (2000). Drosophila CRY is a deep brain circadian photoreceptor. Neuron, 26(2), 493-504. https://doi.org/10.1016/s0896-6273(00)81181-2

22. Gao, X., \& Pan, D. (2001). TSC1 and TSC2 tumor suppressors antagonize insulin signaling in cell growth. Genes \& development, 15(11), 1383-1392. https://doi.org/10.1101/gad.901101

23. Géminard, C., Rulifson, E. J., \& Léopold, P. (2009). Remote control of insulin secretion by fat cells in Drosophila. Cell metabolism, 10(3), 199-207. https://doi.org/10.1016/j.cmet.2009.08.002 
24. Gerstner, J. R., Bremer, Q. Z., Vander Heyden, W. M., Lavaute, T. M., Yin, J. C., \& Landry, C. F. (2008). Brain fatty acid binding protein (Fabp7) is diurnally regulated in astrocytes and hippocampal granule cell precursors in adult rodent brain. PloS one, 3(2), e1631. https://doi.org/10.1371/journal.pone.0001631

25. Glossop, N. R., \& Hardin, P. E. (2002). Central and peripheral circadian oscillator mechanisms in flies and mammals. Journal of cell science, 115(Pt 17), 3369-3377.

26. González, A., \& Hall, M. N. (2017). Nutrient sensing and TOR signaling in yeast and mammals. The EMBO journal, 36(4), 397-408.

https://doi.org/10.15252/embj.201696010

27. Green, C. B., Takahashi, J. S., \& Bass, J. (2008). The meter of metabolism. Cell, 134(5), 728-742. https://doi.org/10.1016/j.cell.2008.08.022

28. Grewal, S. S., Evans, J. R., \& Edgar, B. A. (2007). Drosophila TIF-IA is required for ribosome synthesis and cell growth and is regulated by the TOR pathway. The Journal of cell biology, 179(6), 1105-1113. https://doi.org/10.1083/jcb.200709044

29. Guertin, D. A., Guntur, K. V., Bell, G. W., Thoreen, C. C., \& Sabatini, D. M. (2006). Functional genomics identifies TOR-regulated genes that control growth and division. Current biology : CB, 16(10), 958-970. https://doi.org/10.1016/j.cub.2006.03.084

30. Hakes, A. E., \& Brand, A. H. (2019). Neural stem cell dynamics: the development of brain tumours. Current opinion in cell biology, 60, 131-138. https://doi.org/10.1016/j.ceb.2019.06.001

31. Hara, R., Wan, K., Wakamatsu, H., Aida, R., Moriya, T., Akiyama, M., \& Shibata, S. (2001). Restricted feeding entrains liver clock without participation of the suprachiasmatic nucleus. Genes to cells : devoted to molecular \& cellular mechanisms, 6(3), 269-278. https://doi.org/10.1046/j.1365-2443.2001.00419.x

32. Hardin, P. E., \& Panda, S. (2013). Circadian timekeeping and output mechanisms in animals. Current opinion in neurobiology, 23(5), 724-731. https://doi.org/10.1016/j.conb.2013.02.018

33. Heisenberg M. (2003). Mushroom body memoir: from maps to models. Nature reviews. Neuroscience, 4(4), 266-275. https://doi.org/10.1038/nrn1074

34. Hermann-Luibl C, \& Helfrich-Foerster C (2015). Clock network in Drosophila. Curr Opin Insect Sci 7:65-70.

35. Hernandez-Verdun D. (2011). Assembly and disassembly of the nucleolus during the cell cycle. Nucleus (Austin, Tex.), 2(3), 189-194. https://doi.org/10.4161/nucl.2.3.16246

36. Hietakangas, V., \& Cohen, S. M. (2009). Regulation of tissue growth through nutrient sensing. Annual review of genetics, 43, 389-410. https://doi.org/10.1146/annurevgenet-102108-134815 
37. Holz, M. K., Ballif, B. A., Gygi, S. P., \& Blenis, J. (2005). mTOR and S6K1 mediate assembly of the translation preinitiation complex through dynamic protein interchange and ordered phosphorylation events. Cell, 123(4), 569-580. https://doi.org/10.1016/j.cell.2005.10.024

38. Homem, C. C., \& Knoblich, J. A. (2012). Drosophila neuroblasts: a model for stem cell biology. Development (Cambridge, England), 139(23), 4297-4310. https://doi.org/10.1242/dev.080515

39. Hughes, M. E., Grant, G. R., Paquin, C., Qian, J., \& Nitabach, M. N. (2012). Deep sequencing the circadian and diurnal transcriptome of Drosophila brain. Genome research, 22(7), 1266-1281. https://doi.org/10.1101/gr.128876.111.

40. Inoki, K., Li, Y., Zhu, T., Wu, J., \& Guan, K. L. (2002). TSC2 is phosphorylated and inhibited by Akt and suppresses mTOR signalling. Nature cell biology, 4(9), 648-657. https://doi.org/10.1038/ncb839

41. Ito, K., \& Hotta, Y. (1992). Proliferation pattern of postembryonic neuroblasts in the brain of Drosophila melanogaster. Developmental biology, 149(1), 134-148. https://doi.org/10.1016/0012-1606(92)90270-q

42. Jouffe, C., Cretenet, G., Symul, L., Martin, E., Atger, F., Naef, F., \& Gachon, F. (2013). The circadian clock coordinates ribosome biogenesis. PLoS biology, 11(1), e1001455. https://doi.org/10.1371/journal.pbio.1001455

43. Kim, E., Goraksha-Hicks, P., Li, L., Neufeld, T. P., \& Guan, K. L. (2008). Regulation of TORC1 by Rag GTPases in nutrient response. Nature cell biology, 10(8), 935945. https://doi.org/10.1038/ncb1753

44. Koyama, T., Texada, M. J., Halberg, K. A., \& Rewitz, K. (2020). Metabolism and growth adaptation to environmental conditions in Drosophila. Cellular and molecular life sciences: CMLS, 10.1007/s00018-020-03547-2. Advance online publication. https://doi.org/10.1007/s00018-020-03547-2

45. Kraft, K. F., Massey, E. M., Kolb, D., Walldorf, U., \& Urbach, R. (2016). Retinal homeobox promotes cell growth, proliferation and survival of mushroom body neuroblasts in the Drosophila brain. Mechanisms of development, 142, 50-61. https://doi.org/10.1016/j.mod.2016.07.003

46. Kurusu, M., Nagao, T., Walldorf, U., Flister, S., Gehring, W. J., \& FurukuboTokunaga, K. (2000). Genetic control of development of the mushroom bodies, the associative learning centers in the Drosophila brain, by the eyeless, twin of eyeless, and Dachshund genes. Proceedings of the National Academy of Sciences of the United States of America, 97(5), 2140-2144. https://doi.org/10.1073/pnas.040564497

47. Kurusu, M., Maruyama, Y., Adachi, Y., Okabe, M., Suzuki, E., \& Furukubo-Tokunaga, K. (2009). A conserved nuclear receptor, Tailless, is required for efficient proliferation and prolonged maintenance of mushroom body progenitors in the Drosophila brain. Developmental biology, 326(1), 224-236. https://doi.org/10.1016/j.ydbio.2008.11.013 
48. Lamia, K. A., Storch, K. F., \& Weitz, C. J. (2008). Physiological significance of a peripheral tissue circadian clock. Proceedings of the National Academy of Sciences of the United States of America, 105(39), 15172-15177. https://doi.org/10.1073/pnas.0806717105

49. Lanet, E., \& Maurange, C. (2014). Building a brain under nutritional restriction: insights on sparing and plasticity from Drosophila studies. Frontiers in physiology, 5, 117. https://doi.org/10.3389/fphys.2014.00117

50. Li, Q., \& Gong, Z. (2015). Cold-sensing regulates Drosophila growth through insulin$\begin{array}{llll}\text { producing cells. Nature communications, } 10083 . & \text { 6, }\end{array}$ https://doi.org/10.1038/ncomms10083

51.Lin, S., Marin, E. C., Yang, C. P., Kao, C. F., Apenteng, B. A., Huang, Y., O'Connor, M. B., Truman, J. W., \& Lee, T. (2013). Extremes of lineage plasticity in the Drosophila brain. Current biology : CB, 23(19), 1908-1913. https://doi.org/10.1016/j.cub.2013.07.074

52. Liu, A. C., Lewis, W. G., \& Kay, S. A. (2007). Mammalian circadian signaling networks and therapeutic targets. Nature chemical biology, 3(10), 630-639. https://doi.org/10.1038/nchembio.2007.37

53. Ma, X. M., Yoon, S. O., Richardson, C. J., Jülich, K., \& Blenis, J. (2008). SKAR links pre-mRNA splicing to mTOR/S6K1-mediated enhanced translation efficiency of spliced mRNAs. Cell, 133(2), 303-313. https://doi.org/10.1016/j.cell.2008.02.031

54. Marcheva, B., Ramsey, K. M., Buhr, E. D., Kobayashi, Y., Su, H., Ko, C. H., Ivanova, G., Omura, C., Mo, S., Vitaterna, M. H., Lopez, J. P., Philipson, L. H., Bradfield, C. A., Crosby, S. D., JeBailey, L., Wang, X., Takahashi, J. S., \& Bass, J. (2010). Disruption of the clock components CLOCK and BMAL1 leads to hypoinsulinaemia and diabetes. Nature, 466(7306), 627-631. https://doi.org/10.1038/nature09253

55. Maszewski, J., \& Kwiatkowska, M. (1984). Number, size, and transcriptional activity of nucleoli during different periods of interphase in antheridial filaments of Chara vulgaris L. Folia histochemica et cytobiologica, 22(1), 9-19.

56. Maurange, C., Cheng, L., \& Gould, A. P. (2008). Temporal transcription factors and their targets schedule the end of neural proliferation in Drosophila. Cell, 133(5), 891902. https://doi.org/10.1016/j.cell.2008.03.034

57. Maury E. (2019). Off the Clock: From Circadian Disruption to Metabolic Disease. $\begin{array}{llll}\text { International journal of molecular sciences, 20(7), } & 1597 .\end{array}$ https://doi.org/10.3390/ijms20071597

58. McCarthy, J. J., Andrews, J. L., McDearmon, E. L., Campbell, K. S., Barber, B. K., Miller, B. H., Walker, J. R., Hogenesch, J. B., Takahashi, J. S., \& Esser, K. A. (2007). Identification of the circadian transcriptome in adult mouse skeletal muscle. Physiological genomics, 31(1), 86-95. https://doi.org/10.1152/physiolgenomics.00066.2007 
59. Mota, M. C., Silva, C. M., Balieiro, L., Fahmy, W. M., \& Crispim, C. A. (2017). Social jetlag and metabolic control in non-communicable chronic diseases: a study addressing different obesity statuses. Scientific reports, 7(1), 6358. https://doi.org/10.1038/s41598-017-06723-w

60. Navé, B. T., Ouwens, M., Withers, D. J., Alessi, D. R., \& Shepherd, P. R. (1999). Mammalian target of rapamycin is a direct target for protein kinase B: identification of a convergence point for opposing effects of insulin and amino-acid deficiency on protein translation. The Biochemical journal, 344 Pt 2(Pt 2), 427-431.

61. Neumüller, R. A., Richter, C., Fischer, A., Novatchkova, M., Neumüller, K. G., \& Knoblich, J. A. (2011). Genome-wide analysis of self-renewal in Drosophila neural stem cells by transgenic RNAi. Cell stem cell, 8(5), 580-593. https://doi.org/10.1016/j.stem.2011.02.022

62. Nijhout H. F. (2003). The control of body size in insects. Developmental biology, 261(1), 1-9. https://doi.org/10.1016/s0012-1606(03)00276-8

63. Panda, S., Hogenesch, J. B., \& Kay, S. A. (2002). Circadian rhythms from flies to human. Nature, 417(6886), 329-335. https://doi.org/10.1038/417329a

64. Paschos G. K. (2015). Circadian clocks, feeding time, and metabolic homeostasis. Frontiers in pharmacology, 6, 112. https://doi.org/10.3389/fphar.2015.00112

65.Patke, A., Young, M. W., \& Axelrod, S. (2020). Molecular mechanisms and physiological importance of circadian rhythms. Nature reviews. Molecular cell biology, 21(2), 67-84. https://doi.org/10.1038/s41580-019-0179-2

66. Potter, C. J., Pedraza, L. G., \& Xu, T. (2002). Akt regulates growth by directly phosphorylating Tsc2. Nature cell biology, 4(9), 658-665. https://doi.org/10.1038/ncb840

67. Ramon-Cañellas, P., Peterson, H. P., \& Morante, J. (2019). From Early to Late Neurogenesis: Neural Progenitors and the Glial Niche from a Fly's Point of View. Neuroscience, 399, 39-52. https://doi.org/10.1016/j.neuroscience.2018.12.014

68. Raught, B., Peiretti, F., Gingras, A. C., Livingstone, M., Shahbazian, D., Mayeur, G. L., Polakiewicz, R. D., Sonenberg, N., \& Hershey, J. W. (2004). Phosphorylation of eucaryotic translation initiation factor 4B Ser422 is modulated by S6 kinases. The EMBO journal, 23(8), 1761-1769. https://doi.org/10.1038/sj.emboj.7600193

69. Rey, G., Cesbron, F., Rougemont, J., Reinke, H., Brunner, M., \& Naef, F. (2011). Genome-wide and phase-specific DNA-binding rhythms of BMAL1 control circadian output functions in mouse liver. PLoS biology, 9(2), e1000595. https://doi.org/10.1371/journal.pbio.1000595

70. Rudic, R. D., McNamara, P., Curtis, A. M., Boston, R. C., Panda, S., Hogenesch, J. B., \& Fitzgerald, G. A. (2004). BMAL1 and CLOCK, two essential components of the circadian clock, are involved in glucose homeostasis. PLoS biology, 2(11), e377. https://doi.org/10.1371/journal.pbio.0020377 
71. Ruggero, D., \& Sonenberg, N. (2005). The Akt of translational control. Oncogene, 24(50), 7426-7434. https://doi.org/10.1038/sj.onc.1209098

72. Russell, R. C., Fang, C., \& Guan, K. L. (2011). An emerging role for TOR signaling in mammalian tissue and stem cell physiology. Development (Cambridge, England), 138(16), 3343-3356. https://doi.org/10.1242/dev.058230

73. Saxton, R. A., \& Sabatini, D. M. (2017). mTOR Signaling in Growth, Metabolism, and Disease. Cell, 168(6), 960-976. https://doi.org/10.1016/j.cell.2017.02.004

74. Shahbazian, D., Roux, P. P., Mieulet, V., Cohen, M. S., Raught, B., Taunton, J., Hershey, J. W., Blenis, J., Pende, M., \& Sonenberg, N. (2006). The mTOR/PI3K and MAPK pathways converge on elF4B to control its phosphorylation and activity. The EMBO journal, 25(12), 2781-2791. https://doi.org/10.1038/sj.emboj.7601166

75. Shi, M., \& Zheng, X. (2013). Interactions between the circadian clock and metabolism: there are good times and bad times. Acta biochimica et biophysica Sinica, 45(1), 61-69. https://doi.org/10.1093/abbs/gms110

76. Shim, J., Gururaja-Rao, S., \& Banerjee, U. (2013). Nutritional regulation of stem and progenitor cells in Drosophila. Development (Cambridge, England), 140(23), 46474656. https://doi.org/10.1242/dev.079087

77. Shingleton, A. W., Estep, C. M., Driscoll, M. V., \& Dworkin, I. (2009). Many ways to be small: different environmental regulators of size generate distinct scaling relationships in Drosophila melanogaster. Proceedings. Biological sciences, 276(1667), 2625-2633. https://doi.org/10.1098/rspb.2008.1796

78. Siegrist, S. E., Haque, N. S., Chen, C. H., Hay, B. A., \& Hariharan, I. K. (2010). Inactivation of both Foxo and reaper promotes long-term adult neurogenesis in Drosophila. Current biology: CB, 20(7), 643-648. https://doi.org/10.1016/j.cub.2010.01.060

79. Sousa-Nunes, R., Yee, L. L., \& Gould, A. P. (2011). Fat cells reactivate quiescent neuroblasts via TOR and glial insulin relays in Drosophila. Nature, 471(7339), 508512. https://doi.org/10.1038/nature09867

80. Stępiński D. (2018). The nucleolus, an ally, and an enemy of cancer cells. Histochemistry and cell biology, 150(6), 607-629. https://doi.org/10.1007/s00418018-1706-5

81. Storch, K. F., Lipan, O., Leykin, I., Viswanathan, N., Davis, F. C., Wong, W. H., \& Weitz, C. J. (2002). Extensive and divergent circadian gene expression in liver and heart. Nature, 417(6884), 78-83. https://doi.org/10.1038/nature744

82. Tennessen, J. M., \& Thummel, C. S. (2011). Coordinating growth and maturation insights from Drosophila. Current biology: $C B$, 21(18), R750-R757. https://doi.org/10.1016/j.cub.2011.06.033

83. Truman, J. W., \& Bate, M. (1988). Spatial and temporal patterns of neurogenesis in the central nervous system of Drosophila melanogaster. Developmental biology, 125(1), 145-157. https://doi.org/10.1016/0012-1606(88)90067-x 
84. Ueda, H. R., Matsumoto, A., Kawamura, M., lino, M., Tanimura, T., \& Hashimoto, S. (2002). Genome-wide transcriptional orchestration of circadian rhythms in Drosophila. The Journal of biological chemistry, 277(16), 14048-14052. https://doi.org/10.1074/jbc.C100765200

85. Walsh, K. T., \& Doe, C. Q. (2017). Drosophila embryonic type II neuroblasts: origin, temporal patterning, and contribution to the adult central complex. Development (Cambridge, England), 144(24), 4552-4562. https://doi.org/10.1242/dev.157826

86. Wang, Y. C., Yang, J. S., Johnston, R., Ren, Q., Lee, Y. J., Luan, H., Brody, T., Odenwald, W. F., \& Lee, T. (2014). Drosophila intermediate neural progenitors produce lineage-dependent related series of diverse neurons. Development (Cambridge, England), 141(2), 253-258. https://doi.org/10.1242/dev.103069

87.Wijnen, H., Naef, F., Boothroyd, C., Claridge-Chang, A., \& Young, M. W. (2006). Control of daily transcript oscillations in Drosophila by light and the circadian clock. PLoS genetics, 2(3), e39. https://doi.org/10.1371/journal.pgen.0020039

88. Xu, K., Zheng, X., \& Sehgal, A. (2008). Regulation of feeding and metabolism by neuronal and peripheral clocks in Drosophila. Cell metabolism, 8(4), 289-300. https://doi.org/10.1016/j.cmet.2008.09.006

89. Yang, S., Liu, A., Weidenhammer, A., Cooksey, R. C., McClain, D., Kim, M. K., Aguilera, G., Abel, E. D., \& Chung, J. H. (2009). The role of mPer2 clock gene in glucocorticoid and feeding rhythms. Endocrinology, 150(5), 2153-2160. https://doi.org/10.1210/en.2008-0705

90.Zhang, H., Stallock, J. P., Ng, J. C., Reinhard, C., \& Neufeld, T. P. (2000). Regulation of cellular growth by the Drosophila target of rapamycin dTOR. Genes \& development, 14(21), 2712-2724. https://doi.org/10.1101/gad.835000

91.Zhu, C. C., Boone, J. Q., Jensen, P. A., Hanna, S., Podemski, L., Locke, J., Doe, C. Q., \& O'Connor, M. B. (2008). Drosophila Activin- and the Activin-like product Dawdle function redundantly to regulate proliferation in the larval brain. Development (Cambridge, England), 135(3), 513-521. https://doi.org/10.1242/dev.010876

92.Zordan, M. A., \& Sandrelli, F. (2015). Circadian Clock Dysfunction and Psychiatric Disease: Could Fruit Flies have a Say?. Frontiers in neurology, 6, 80. https://doi.org/10.3389/fneur.2015.00080 


\section{Figure legends}

Figure 1. Light and circadian clock control neuroblast growth. A) Neuroblasts were marked using aPKC (green) and Mir (red), Phospho-histone H3 (pH3, green) was used to mark chromatin during mitosis; B) central brain NBs size distribution of wild-type larvae grown at different light regimes, cry ${ }^{01}$ and $p r^{01}$ mutant lines (number of measured neuroblasts for each genotype and light conditions are indicated on Fig 1C) where the NBs in wild type mainly distributed within 120 to $170 \mu \mathrm{m}^{2}$, NBs in wild-type larvae grown under DD condition and per ${ }^{01}$ mutants range between 90 to $140 \mu \mathrm{m}^{2}$, whereas cell size for larvae under LL condition and $c r y^{01}$ are distributed between 110 to $150 \mu \mathrm{m}^{2}$; C) Average NBs sizes are significantly reduced in $c r y^{01}$ and $p e r^{01}$ mutant flies, which were kept under LD condition, as well as in wild type flies developing under different light conditions $(p<0.0001)$; D) Difference in neuroblast sizes were observed at all larval stages $(p<0.001, p<0.01)$. At least 10 brains were analysed for each genotype and different light conditions. Each data represents the mean obtained from the number of measured NBs \pm the max and min size distribution. The number of measured NBs are indicated below each box.

Figure 2. Effect of light and the molecular clock on MB and Type II neuroblast sizes and proliferation pattern. A) Miranda (Mir-blue) was used as a neuroblast marker, Tailles (TII-green) and Dachshund (Dac-blue) were used to mark MB NB derived Kenyon cells and GMCs, correspondingly, and phalloidin (red) was used as a marker for actin. There was a significant reduction in MB NB size C) under DD (constant darkness) condition and in per ${ }^{01}$ mutant flies ( $p<0,0001)$; D) The cell proliferation was also affected according to the number of $\mathrm{TII}^{+}$cells $(p<0,0001)$; B) Type II NBs were marked with GFP (green) and in addition with NB specific marker Miranda, Dpn (red) and Ase (blue) were used to distinguish progenies of Type II NBs. Type II neuroblast sizes E) as well as the number of mINPs F) were significantly reduced in flies under DD compare to LD conditions, according to the number of $\mathrm{Dpn}^{+}$cells $(p<0,0001)$. At least 10 brains were analysed for each genotype and different light conditions; each data represents the mean obtained from the number of measured NBs or counted progenies \pm the max and min size distribution. The number of measured NBs or counted progenies are indicated below each box.

Figure 3. Nucleolar size is affected by light and the circadian clock. A) Apical and basal cortical localization of aPKC (green) and Miranda (Mir-red) (as markers for cell polarity) in NB were not disturbed in per ${ }^{01}$ mutants or wild-type animals grown under DD condition. Phospho-histone $\mathrm{H} 3$ ( $\mathrm{pH} 3$ ) was used to mark chromatin during mitosis. Correct alignment of chromatin with respect to the apico-basal axis indicates proper spindle orientation upon cell division axis. At least 10 brains were analysed for each genotype and different light conditions; B) Neuroblasts were marked using aPKC (green) and Mir (red), Lamine (blue) was used to mark nuclear membranes and Nop5 (green) was used as a nucleolar marker; C) ucleolar sizes are significantly reduced in wild-type grown under DD conditions and per $r^{01}$ mutants compare to wild-type in LD situation $(p<0.0001)$. At least 10 brains were analysed for each genotype and different light conditions; each data represents the mean obtained 
from the number of measured nucleolus \pm the max and min size distribution. The number of analysed neuroblasts are indicated below of each box; D) Nucleolar size distribution in per ${ }^{01}$ mutant and wild-type larvae grown under DD and LD light conditions.

Figure 4. Influence of light on transcription and activation of dAkt and dS6k kinases. A) and C) expression of $d A k t$ and $d S 6 k$ within 24-hour time course under LD and DD conditions. Each time point represents the mean \pm standard error of the mean (SEM) obtained from three biological replicates, each repeated in triplicates. As an internal control rp49 was used; B) and D) representative blots of $3^{d}$ instar larval brain extract for dpAkt and dpS6k at different time points during 24-hour, which were grown under different light regimes. $\alpha$-Tubulin was used as a loading control. Dot plots show measurements of dAkt and dS6k phosphorylation level out of seven and three biological replicates respectively, normalized to $\alpha$-Tubulin. Box plots display the sum of all time points measurements of dAkt and dS6K phosphorylation for LD and DD conditions $(p<0.001$ and $p<0.01)$.

Figure 5. Clock dependent transcription and phosphorylation of dAkt and dS6k kinases. A) and C) RT-qPCR analysis of $d A k t(A)$ and $d S 6 k(C)$ transcription in between wild type and per ${ }^{01}$ mutant flies. Each bar represents the mean \pm standard error of the mean (SEM) obtained from three biological replicates, each repeated in triplicates. As an internal control rp49 was used ( $p<0.01$ and $p<0.004$, respectively); Western blots showing dpAkt (B) and dpS6k (D) phosphorylation levels in wild type and per $013^{\text {rd }}$ instar larval brains. $\alpha$-Tubulin was used as a loading control. Graphs represent measurements of dpAkt and dpS6k phosphorylation level out of three biological replicates normalized to $\alpha$-Tubulin (mean $\pm S E M$ ) $(p<0.0001$ and $p<0.001)$. 


\section{Figure 1}

A

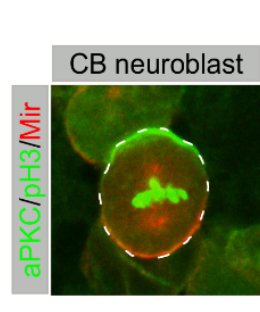

B

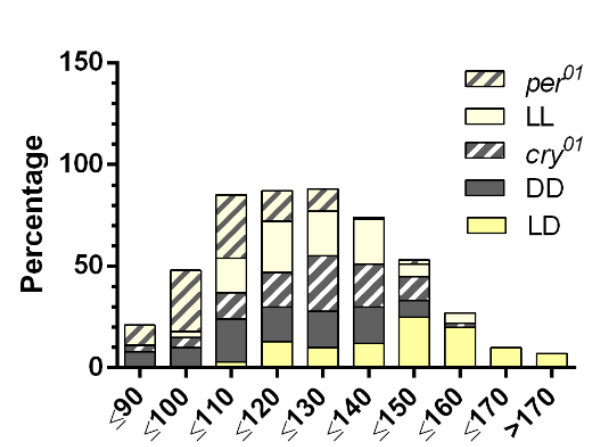

Neuroblast area $\left(\mu \mathrm{m}^{2}\right)$

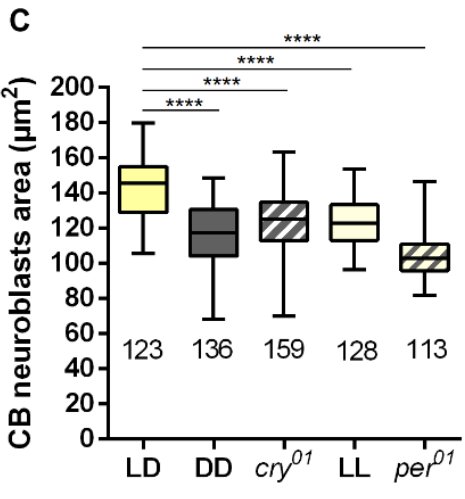

D

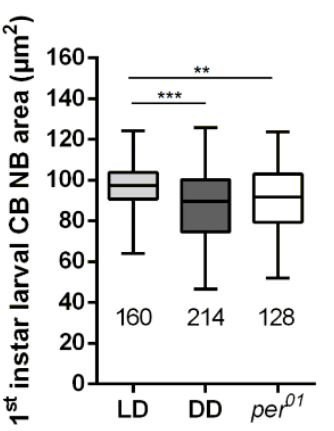

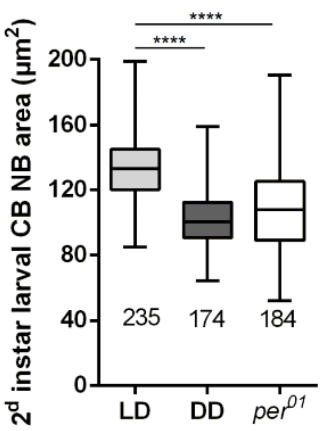

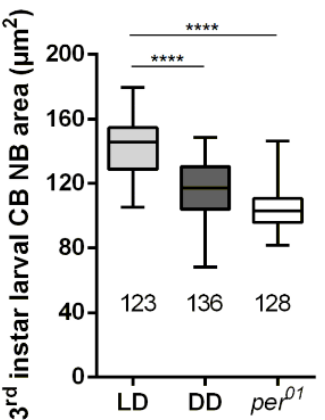


bioRxiv preprint doi: https://doi.org/10.1101/2020.08.07.241208; this version posted August 7, 2020. The copyright holder for this preprint (which was not certified by peer review) is the author/funder, who has granted bioRxiv a license to display the preprint in perpetuity. It is made available under aCC-BY-NC-ND 4.0 International license.

Figure 2

A

MB and

Type I GMC neuron

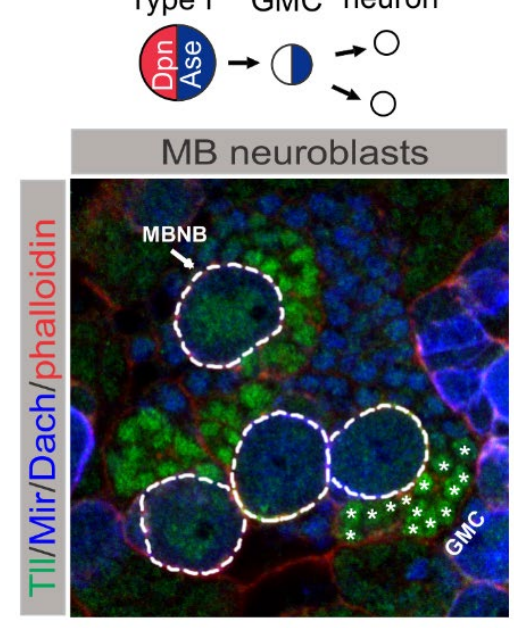

C

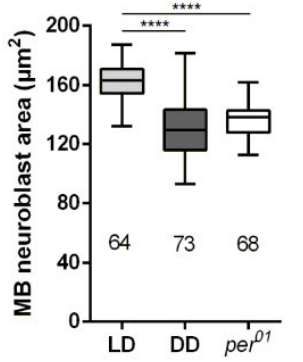

D

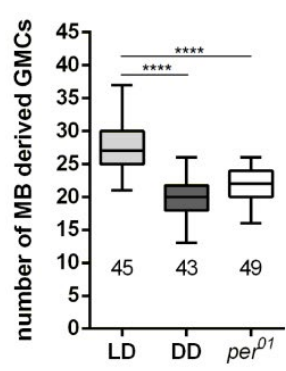

B

Type II iINP ilNP mINPGMC neuron

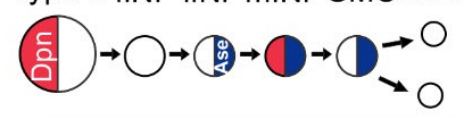

Type II neuroblasts

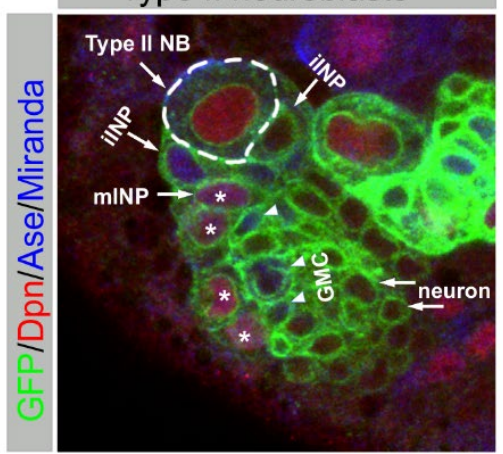

E

$\mathbf{F}$

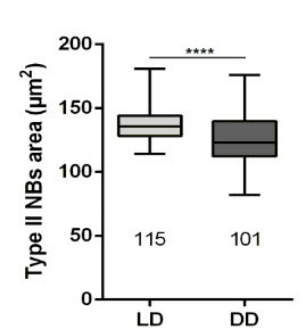

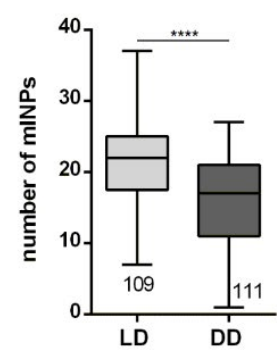


bioRxiv preprint doi: https://doi org/10.1101/2020.08 07.241208; this version posted August 7, 2020. The copyright holder for this preprint (which was not certified by peer review) is the author/funder, who has granted bioRxiv a license to display the preprint in perpetuity. It is made available under aCC-BY-NC-ND 4.0 International license.

\section{Figure 3}

A

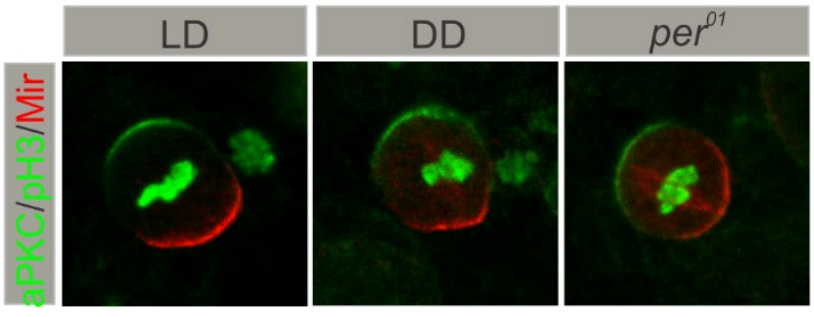

B

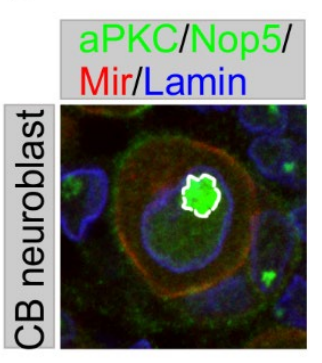

C

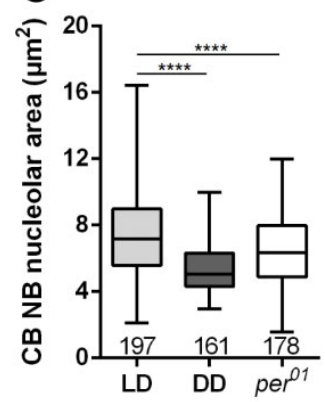

D

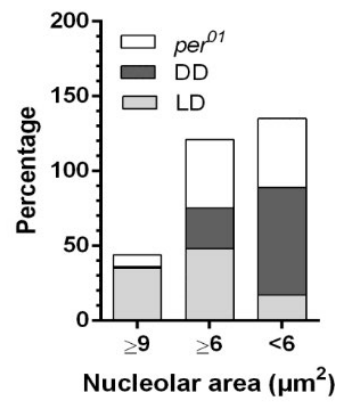




\section{Figure 4}

A

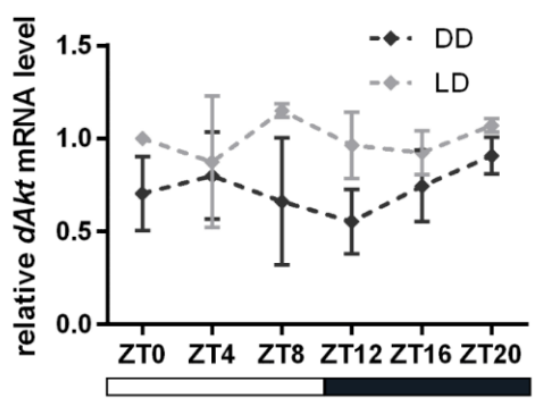

B

ZT 0 ZT 4 ZT 8 ZT 12 ZT 16 ZT 20

LD DD LD DD LD DD LD DD LD DD LD DD

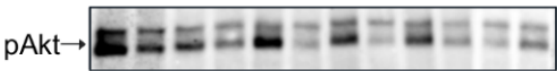

C

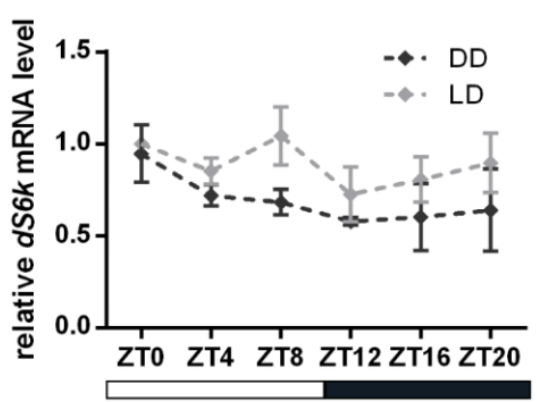

D

ZT 0 ZT 4 ZT 8 ZT 12 ZT 16 ZT 20

LD DD LD DD LD DD LD DD LD DD LD DD

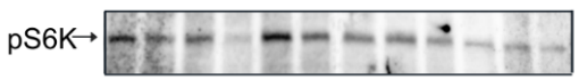

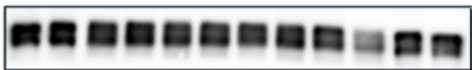

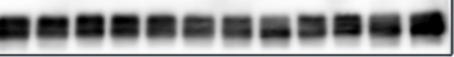
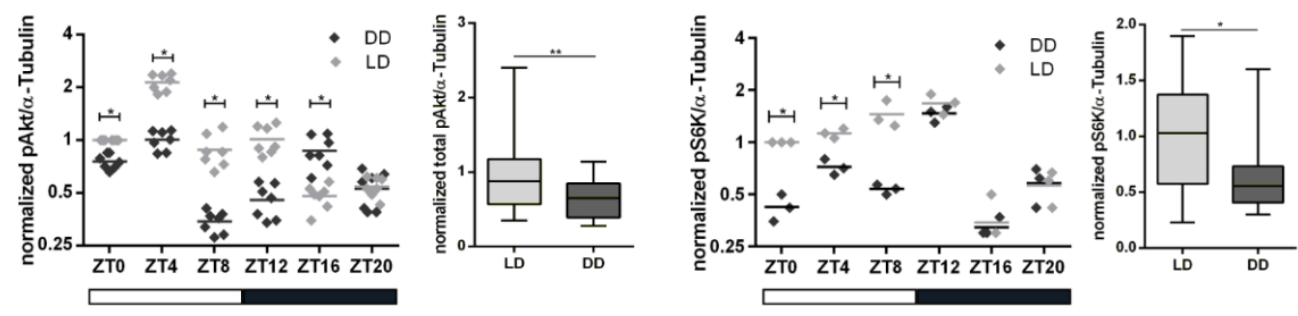
bioRxiv preprint doi: https://doi.org/10.1101/2020.08.07.241208; this version posted August 7, 2020. The copyright holder for this preprint (which was not certified by peer review) is the author/funder, who has granted bioRxiv a license to display the preprint in perpetuity. It is made available under aCC-BY-NC-ND 4.0 International license.

\section{Figure 5}

A

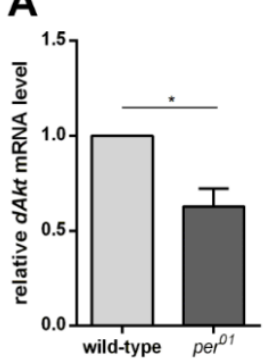

B

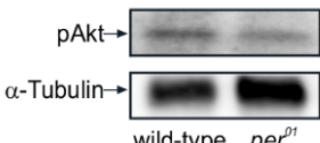

wild-type per ${ }^{p 1}$

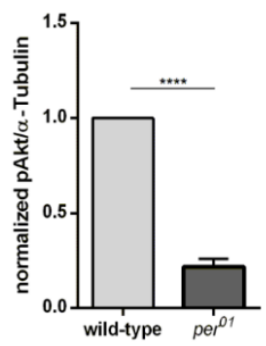

C

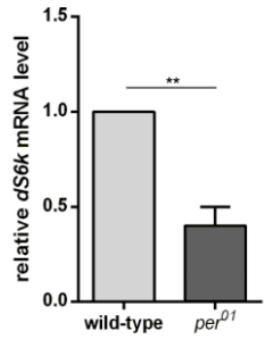

D
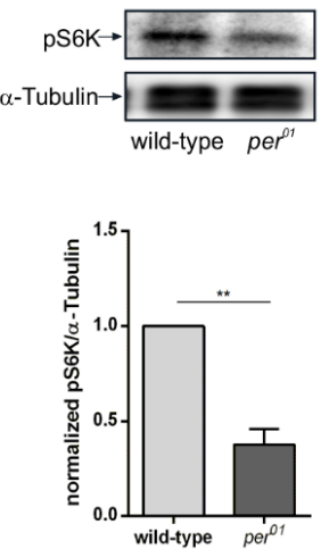